\title{
Utilisation of sustainable green energy in young generation
}

\author{
Yonik M Yustiani ${ }^{1}$, Astri Hasbiah ${ }^{1 *}$, and Latifah Mutmainah ${ }^{1}$ \\ ${ }^{1}$ Universitas Pasundan, Department of Environmental Engineering, J1. Dr. Setiabudhi 193 Bandung 40153, Indonesia
}

\begin{abstract}
Indonesia has many green energy potencies to replace the fossil-based conventional energy. However, the use of this conventional energy is still in dominant. It is understandable that older generations are difficult to change their habits in using green energy for various reasons. Whereas the younger generation are expected to starts using environmentally friendly energy, in the form of new and renewable energy. This study aims to determine the tendency of young people to use renewable energy. 60 respondents were selected from department of environmental engineering students, Pasundan University in Bandung, Indonesia. The respondents range from first to fourth year students. Assumption used in respondents selection was student with environmental engineering educational background will have knowledge on renewable energy. This research conducted through questionnaires. The results show that only $10 \%$ of the respondents have used the renewable energy, i.e. solar energy. Whereas $90 \%$ of respondents do not use renewable energy due to lack of knowledge on how to start using it. Nevertheless, $97 \%$ of respondents consider that using green energy is a proud thing. From a variety of green energy alternatives, $50 \%$ of the students consider solid waste as the most potential source of renewable energy in Indonesia.
\end{abstract}

\section{Introduction}

Indonesia has a population of more than 250 million people. Therefore, the country requires enormous amount of energy. The use of fossil fuels is the dominant source of energy in Indonesia. Up to $90 \%$ of energy used are originated from fossil fuels [1]. Oil and coal are sources of power plants used by Indonesia's national electricity company. It serves the electricity demanded both in cities and rural areas. Fossil fuels are used not only to meet energy demand in electricity but also in transportation, industry, trade, etc. Fossil-based energy sources has high environmental pollution potential. The use of oil in transportation has shown a negative impact on air quality, especially in urban areas with high concentrations of air pollutant parameters such as $\mathrm{CO}, \mathrm{Pb}$, etc. Indonesia's environmental quality deterioration is inevitable due to its increasing demand for energy.

The potential of alternative energy in Indonesia is high. Indonesia's location in the tropics provides a high opportunity to utilize various green energy alternatives. The new and renewable energies available are solar, wind, water/micro-hydro and biomass. This alternative energy has a lower pollution potential. Whereas, fossil fuels have high pollution potential during extraction, distillation and combustion processes. Energy sources can be referred to as environmentally friendly in terms of low pollution generated during its deposition, exploitation, processing and usage. The dominance of fossil fuels usage is difficult to change due to different interests of the government and communities. Low number of renewable energy usage is caused by economic and efficiency factors [2]. Consequences of fossil based energy consumption are ignorance of environmental sustainability, sustainability, and health aspects.

Difficulty of paradigm change on using alternative energy are understandable among conservative older people. However, younger generation are expected to shift towards using renewable energy. Young people are expected to play an active role to improve environmental condition through green energy consumption. This study aims to determine the tendency of young people to use renewable energy. The results of the study can be use as the basis to examine the young generation understanding and interests on using renewable energy.

\section{Methods}

This research was conducted through questionnaires. The selected respondents were asked a number of questions about renewable energy. Information obtained from the distributed questionnaires are:

- Initial knowledge of renewable energy

- Source of knowledge of renewable energy

- Types of renewable energy known and used

- Constraints on renewable energy usage

- The most potential source of renewable energy

- Family views on renewable energy

\section{Result and discussion}

The number of respondents selected in this research was 60 students' with $10 \%$ of 1 st year student, $40 \%$ of 2 nd year student, $30 \%$ of 3 rd year student and $20 \%$ of 4 th year

\footnotetext{
*Corresponding author: astrihasbiah@unpas.ac.id
} 
student. The research result shows that $40 \%$ of respondents' initial knowledge of renewable energy was obtained in senior high school. Whereas $13 \%$ of respondents obtain the knowledge since elementary school, 20\% since junior high school and 8\% after graduated from high school. The inclusion of environmental subjects in schools has played an important role in the introduction of environmental conservation from an early age [3]. Previously Indonesian people have local wisdom in conserving the environment, however the understanding and practice of the wisdom are vanished [4]. Parents' influence on children's behaviour in their current environmental conservation efforts is also not strong [3]. Currently the most influential source of renewable energy information is school. Another influential sources to increase environmental conservation knowledge are television and written media. Figure 1 shows the respondent initial knowledge of renewable energy. While Figure 2 shows the percentage of initial knowledge sources of renewable energy.

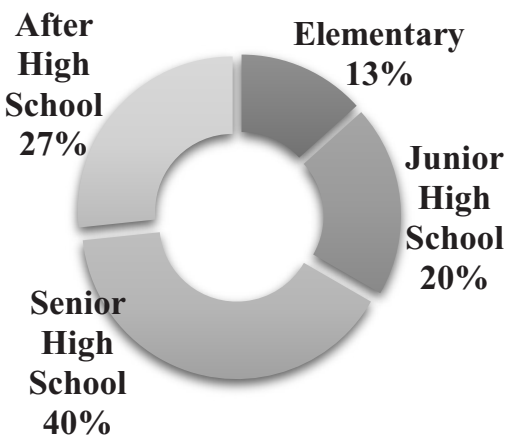

Fig. 1. The respondent initial knowledge of renewable energy.

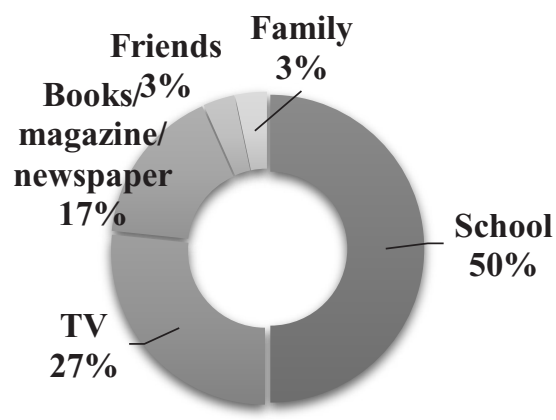

Fig. 2.Initial knowledge sources of renewable energy.

Respondents selected has sufficient knowledge of renewable energy. However, only $10 \%$ of the respondents have used this alternative energy. The type of energy used is solar energy. $90 \%$ of respondents have not use renewable energy. Yet, 93\% of respondents stated their interest on using renewable energy. Mostly the respondents' reason of not using the renewable energy is unawareness on how to start using renewable energy. Another reasons are high cost of renewable energy instalment and difficulties in finding applicable sources.
Education is a tool that can be utilized to increase knowledge and awareness of young people in the implementation of green energy sources. Inadequate real life examples of renewable energy usage has cause low willingness of the respondents to use the alternative energy in everyday life. Moreover, $73 \%$ of the respondents consider the renewable energy popularity among the younger generation is low. However, 90\% of respondents stated that using renewable energy is a proud thing. Interestingly, $50 \%$ of the respondents answered solid waste as the most potential source of alternative energy. Whereas $30 \%, 13 \%$ and $7 \%$ of the respondents answered solar power, water and wind respectively. Another environmental problem faced by Indonesia is poor solid waste management. By utilizing solid waste to generate energy, two urban problems will be managed. However, higher attention is required because energy generation from solid waste must be handled carefully in order to avoid new environmental problems. Combustion technology can lead to severe air pollution. Figure 3 shows the results of questioner on the most potential renewable energy that can be applied in Indonesia.

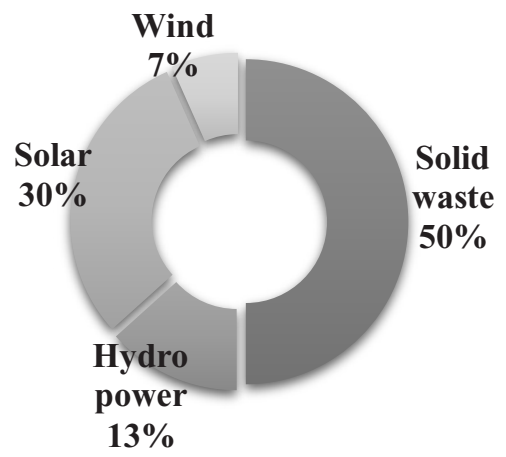

Fig. 3. The most potential renewable energy that can be applied in Indonesia.

Based on the respondents' family condition, 73\% of the respondents' family are not using renewable energy. Public perceptions of a more environmentally friendly energy vary greatly depending on the level of knowledge. In addition, socio-demographic character factors will also affect a person in responding to renewable energy [5].In general, the level of young generation knowledge of renewable energy is good, yet the application is still low. Government's role is important to overcome this issue. For example through economic incentives that benefit the community who use the renewable energy [6]. In addition, the most important thing is to develop values of protecting the environment and natural resources in every level of society [7]. Education is important in raising awareness on sustainable energy usage among young generation [8].

\section{Conclusions}

In conclusion, younger generation already have sufficient knowledge on alternative energy to replace fossil fuels. However the popularity of using this energy alternative is still low. The biggest constrain is unawareness on how to start using renewable energy in daily life. Even though the popularity is low, the younger generation assume that 
using green energy is a proud thing. Government should take part through policy making that can attract the usage of renewable energy. In addition, education is also important to raise awareness of renewable energy usage among young generation.

\section{References}

1. I. Sukarno, H. Matsumoto, L. Susanti, R. Kimura. Int. J. of Ener Econ and Pol 5, 360-373 (2015)

2. M G. Rabbani, C T. Sattary, M R A. Mamun, M M. Rahman, M N H. Khan. Indo J of Elect Eng and Comp Sci 5, 290-298 (2017)

3. I. Rachman, T. Matsumoto, Y M. Yustiani. Sampurasun e-Journal 1, 1-7 (2015)

4. A W. Hasbiah. Sampurasun e-Journal 1, 8-14 (2015)

5. M M E. Moula, J. Maula, M. Hamdy, T. Fang, N. Jung, Lahdelma. Int J of Sustain Built Env 2. 89-98 (2013)

6. A. Botelho, L M C. Pinto, L. Lourenço-Gomes, M. Valente, S. Sousa, S. Energy Procedia 106. 73-86 (2016)

7. C. Demski, C. Butler, K A. Parkhill, A. Spence, N F. Pidgeon. Global Env Change 34. 59-69 (2015).

8. K. Takacs-Gyorgy, S. Doman, A. Tamus, Z. Palkova, Visegrad. J on Bioecon and Sus Dev 2. 36-41 (2015) 